
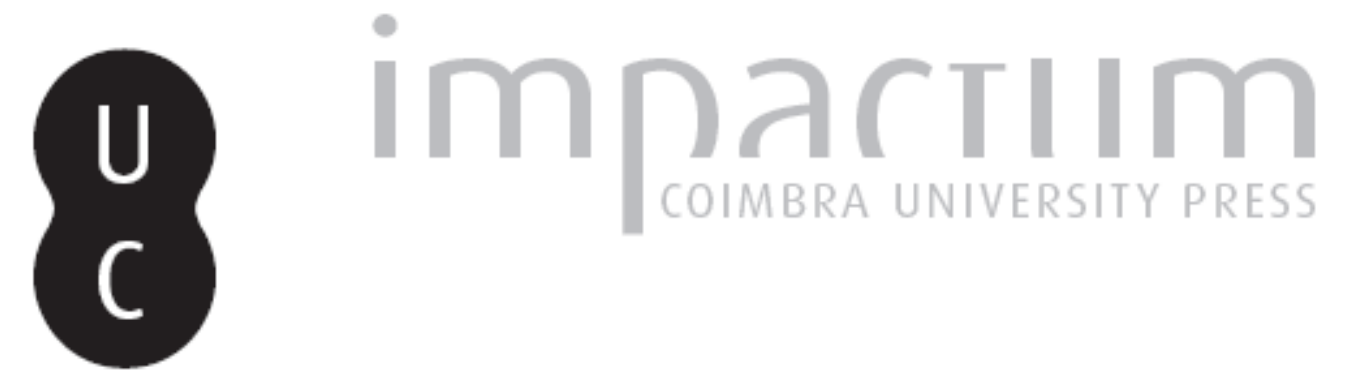

\title{
A liberdade da imprensa agrilhoada
}

\section{Autor(es): $\quad$ Guedes, Marco Aurelio Peri}

Publicado por: Universidade Católica de Petrópolis

URL persistente:

URl:http://hdl.handle.net/10316.2/33863

DOI:

DOI:http://dx.doi.org/10.14195/2175-0947_2-1_4

Accessed : $\quad$ 26-Apr-2023 14:28:21

A navegação consulta e descarregamento dos títulos inseridos nas Bibliotecas Digitais UC Digitalis, UC Pombalina e UC Impactum, pressupõem a aceitação plena e sem reservas dos Termos e Condições de Uso destas Bibliotecas Digitais, disponíveis em https://digitalis.uc.pt/pt-pt/termos.

Conforme exposto nos referidos Termos e Condições de Uso, o descarregamento de títulos de acesso restrito requer uma licença válida de autorização devendo o utilizador aceder ao(s) documento(s) a partir de um endereço de IP da instituição detentora da supramencionada licença.

Ao utilizador é apenas permitido o descarregamento para uso pessoal, pelo que o emprego do(s) título(s) descarregado(s) para outro fim, designadamente comercial, carece de autorização do respetivo autor ou editor da obra.

Na medida em que todas as obras da UC Digitalis se encontram protegidas pelo Código do Direito de Autor e Direitos Conexos e demais legislação aplicável, toda a cópia, parcial ou total, deste documento, nos casos em que é legalmente admitida, deverá conter ou fazer-se acompanhar por este aviso.

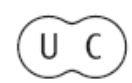



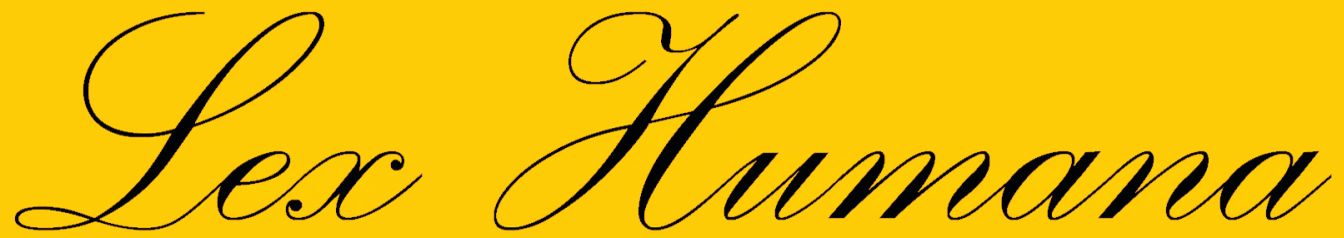

Revista do Programa de Pós-Graduação em Direito da UCP

ISSN(e) 2175-0947

Universidade Católica de Petrópolis Rua Benjamin Constant, 213 - Petrópolis - Centro CEP 25610-130

Tel: (24) 2244-4000 E-mail: lexhumana@ucp.br 


\title{
A Liberdade DA IMPRENSA AgrilHoAdA
}

\author{
Ms. Marco Aurelio Peri Guedes ${ }^{1}$
}

Resumo

O presente trabalho aborda caso decidido no ano de 2009 MCRecl. no 9.428 - pelo STF, envolvendo possível censura ao jornal O Estado de São Paulo. O jornal publicou matéria sobre operação da Polícia Federal designada Boi Barrica, envolvendo entre tantas outras pessoas o empresário Fernando Sarney, filho do então presidente do Senado José Sarney. O empresário, então, ingressa com ação junto ao T.J.D.F. a fim de tutelar o seu direito fundamental à intimidade, que estaria sendo violado pelo jornal. Medida liminar favorável the é concedida por desembargador daquele tribunal, que havia sido anteriormente indicado politicamente pelo Senador José Sarney - pai do empresário. Sem o conhecimento de todos os detalhes, poderíamos dizer que ponderação de interesses foi realizada - liberdade de imprensa e direito à privacidade - e direitos fundamentais foram protegidos, tendo o poder judiciário agido proativamente em sua defesa - sob uma leitura de ativismo judicial. Contudo, o que se observou foi a expressão de práticas oligárquicas a influenciar politicamente a composição do poder judiciário com vistas a dirigir suas decisões, denotando a força do patrimonialismo na república e a fragilidade de nossa constituição. Assim, teria se estabelecido uma censura em via oblíqua à liberdade de imprensa em plena vigor de

1 Mestre em Teoria do Estado e Direito Constitucional pela Pontifícia Universidade Católica do Rio de Janeiro (1997). Professor Assistente de Ciência Política e Direito Constitucional da UCAM. Professor convidado da Pós-graduação lato sensu em Direito Público - UCAM/Centro, desde 2007. Professor Assistente de Direito Público (D.E.) da UFRRJ - 2009. 
um Estado democrático e social de direito, a ferir mortalmente nossas liberdades públicas e a constituição. Lembre-se que a constituição de 1988 veda todas as formas de censuta. Precisamos compreender o significado desta decisão e reverter este quadro de insegurança à liberdade de imprensa.

Palavras-chave: Liberdade de imprensa. Constituição de 1988. O caso do jornal O Estado de São Paulo. A censura revisitada.

\section{Abstract}

This paper deals with the case decided by theSTF - the Brazilian Supreme Court, procedure MCRecl. number 9.428, implying possible censorship to the newspaper "O Estado de São Paulo". The newspaper published issue about a police operation, called Boi Barrica, conducted by the Brazilian Federal Police, involving the businessman Fernando Sarney, the president of the Brazilian Senate José Sarney's son, among many other people. The businessman brought an action against the newspaper in the T.J.D.F. - the Federal District Law Court, in order to protect his fundamental right to intimacy, which would have been violated. A favorable restraining order was granted to him by a judge of the Law Court, previously appointed by the Senator José Sarney, the businessman's father. It is possible to say that fundamental rights were balanced prior to the decision - the freedom of the press and the right to intimacy -, thus entirely protected, having the Judiciary acted in defense of them, accordingly to judicial activism. It ought to be pointed out the schemes of an oligarchy capable of having political influence on the Judiciary members with the purpose of controlling the decisions, which reveals the power of a patriarchal view in the Republic and the fragility of our Constitution. It might 
have been accomplished a slanting mechanism of censorship against the freedom of the press in a full democratic and social State of Law, wounding deeply the public liberties and the Constitution. It should be emphasized that the Brazilian Constitution of 1988 forbids all forms of censorship. The meaning of the decision must be well understood to guarantee the full extent of the freedom of the press.

Key words: Liberty of the press. Constitution of 1988. The case of the State of São Paulo newspaper. Censorship.

Libertas quae sera tamen. Inconfidência Mineira - séc. XVIII.

\section{Introdução}

A Constituição de 1988 no caput do artigo $5^{\circ}$ dispõe que a liberdade é um dos direitos fundamentais do cidadão e como tal deve ser tutelado pelo Estado. A liberdade é um valor que foi eleito pela sociedade brasileira e pelo constituinte de 1986 como algo caro a ser defendido, a fim de evitar o retorno a experiências autoritárias ou ditatoriais, pelas quais tantas vezes passou. Sob o ponto de vista histórico, a liberdade é um objeto de nosso desejo desde a Inconfidência Mineira, mas que precisou passar por muitas tormentas de exceção constitucional até chegar à atual constituição.

Para tanto, a noção de liberdade que nos foi trazida pelos pais da Constituição projeta-se da forma mais ampla, conquanto não o seja em caráter absoluto. É de se lembrar que não podemos falar na existência de direitos absolutos, pois muitas vezes o operador do direito e os acadêmicos deparam com situações limite em que devem 
realizar um juízo de ponderação quando do conflito entre direitos fundamentais, pesando qual valor deve prevalecer no caso concreto.

Quando estudamos Direito Civil na Faculdade de Direito, aprendemos que a propriedade obriga. O proprietário deve criar um vínculo com o bem, móvel ou imóvel, realizando todos os atos necessários à expressão de dominium. Tal comprometimento se reflete pela manutenção e conservação do bem, pagamento de tributos, assim como pela realização de sua função social nos termos da Constituição. Do mesmo modo, podemos afirmar que a liberdade também obriga, desta feita indistintamente a todos os cidadãos da polis. Neste caso, o comprometimento passa pelo cuidado e pela atenção que devem ser devotados pela cidadania às instituições democráticas: o respeito à lei, o agir de urbanidade com os semelhantes, a elevação dos valores republicanos, a manutenção e constante renovação do espírito cívico e o trato diário à liberdade.

Propriedade e liberdade: valores próprios do liberalismo político oitocentista que nos foram legados constitucionalmente e que estiveram presentes em todas as nossas constituições. Seu gérmen estaria nas revoluções americana de 1776 e francesa, de 1789, e seus frutos são colhidos até hoje por nossa sociedade, que, de maneira geral, nunca os repudiou - muito ao contrário. Valores caros ao liberalismo e que constituem os bastiões da democracia liberal, pois que contêm historicamente neste ambiente as arremetidas do Estado com viés autoritário, como podemos verificar na história constitucional inglesa pela Magna Charta libertatis de 1215.

Nosso objetivo, neste trabalho, é chamar a atenção para a restrição judicial que foi imposta ao jornal O Estado de São Paulo, em 2009, por haver publicado uma série de reportagens sobre operação da Polícia Federal chamada Boi Barrica, que apresentava indícios de envolvimento do empresário Fernando Sarney, filho do Presidente 
do Senado José Sarney, em condutas supostamente criminosas. No âmbito do estado democrático de direito e mais de vinte e seis anos depois da redemocratização, é de causar espanto e suscitar temores que se possa cogitar uma forma oblíqua de censura. Por ocasião da elaboração deste trabalho, passados mais de duzentos e setenta dias, o jornal ainda se encontra agrilhoado judicialmente e impedido de publicar notícias sobre o caso.

\section{A liberdade de imprensa na constituição de $\mathbf{1 9 8 8}$}

A liberdade de expressão consiste numa grande conquista das revoluções liberais dos séculos XVIII e XIX, na América do Norte e na Europa. Podemos entender que consiste em direito público subjetivo do cidadão de poder expressar seu pensamento, sua opinião e sua visão de mundo no meio social, sem o receio de sofrer qualquer ordem de represálias, de outrem ou do Estado - principalmente. Tal liberdade, contudo, deve ser compatibilizada em seu exercício com o respeito às diferenças de opinião e de pensamento de terceiros, tendo em vista o vezo democrático e plural de nossa sociedade. O excesso na manifestação dessa liberdade deve ser punido cível e criminalmente, na forma da lei.

A liberdade de expressão é uma das maneiras pelas quais o indivíduo desenvolve a sua personalidade. Por meio dela, o cidadão interage na polis com os seus semelhantes, trocando reflexões, idéias, opiniões, criticando propostas e sendo criticado. A sua existência permite identificar de modo claro a noção de sociedade plural e democrática que nos traz a Constituição da República.

Uma projeção da liberdade de expressão é a liberdade de imprensa. Com a invenção da imprensa por Guttenberg - em meados do século XV - e a possibilidade de difusão de idéias e pensamentos 
numa escala cada vez maior, encontramos na mídia impressa ou jornais diários, dentre outros veículos de mídia, um instrumento capaz de captar a atenção e catalisar o debate público de idéias entre grandes massas populacionais. E não apenas isto. A difusão do conhecimento em tal escala disponibiliza ao bom gestor público, a par do trabalho de informação da coletividade desempenhado pela imprensa, um cabedal de meios próprios e adequados para a construção de uma educação republicana, conscientizando e despertando o povo para o agir cidadão.

De início, o poder que a imprensa refletia foi percebido pelos regimes monárquicos absolutistas que lograram eficazmente controlar, através da censura prévia ou mesmo com entraves burocráticos ou severos ônus fiscais. Com as revoluções liberais do séc. XVIII - americana, de 1776, e francesa, de 1789 - a imprensa tornouse a linha de frente na defesa pela liberdade. A verdade só atemoriza os déspotas e autocratas de plantão, que receiam a transparência e exposição públicas.

Apesar da onda de redemocratização da América Latina nos anos 1980 e 1990, percebe-se um contundente retrocesso político no continente pelo renascimento do populismo demagógico e autoritário sob uma roupagem constitucionalmente democrática. No Brasil, a ameaça à liberdade de imprensa não foi ainda politicamente personificada, embora ela já se faça presente de forma diluída em inexplicáveis e injustificáveis decisões esporádicas de magistrados de primeiro grau pelo país, silenciando rádios e jornais. O exemplo mais recente é o que trataremos agora, envolvendo o jornal O Estado de São Paulo.

3. O caso Estado de São Paulo - Reclamação n ${ }^{\circ} 9.428$

http://www.ucp.br/html/joomlaBR/lexhumana/lexhumana.htm 
Este artigo se baseia no estudo de dois casos decididos pelo STF em 2009: a ADPF 130, que resultou na declaração de inconstitucionalidade da Lei de Imprensa, e a MCRecl. $\mathrm{n}^{\circ}$ 9.428, tendo como reclamante o jornal O Estado de São Paulo, esta com supedâneo naquela ADPF pelo caráter transcendente de suas razões determinantes e pelo fato de, em voto vencido, os Ministros Celso de Mello, Ayres Britto e Carmen Lúcia, especialmente os dois primeiros, entenderem ser o poder geral de cautela a nova face da censura prévia ao exercício da liberdade de imprensa.

O voto vencido reflete a base dogmática a partir da qual se desdobram as reflexões neste artigo, trazendo-nos questionamentos e observações feitos pelos ministros do Supremo Tribunal Federal, envolvendo uma possível deturpação do instituto processual da tutela cautelar como instrumento de censura a meios de comunicação (mídia impressa, televisiva e radiofônica, etc.) por determinados órgãos do poder judiciário, notadamente magistrados de primeira instância. $\mathrm{O}$ registro feito pelos ministros do STF acima indicados revela de modo preocupante o possível comprometimento dos direitos fundamentais ao sabor de convicções pessoais de magistrados sujeitos a influências políticas, cujas decisões terminam por se sobrepor à vontade do poder constituinte originário no tema ora versado.

Outrossim, o emprego de tal expediente denotaria a fragilidade de nossa Constituição e da tutela dos direitos fundamentais, enquanto não revisto este entendimento. É certo que o Supremo Tribunal Federal é uma corte política e que suas decisões são eivadas de conteúdo político, mas a decisão da corte na MCRecl. $n^{\circ} 9.428$ seria demonstrativa do quão frágil a Constituição poderia restar, quando o mundo do político se sobrepõe em demasia ao discurso jurídico, mesmo no âmbito do pretório excelso.

Até então, considerada a história constitucional da liberdade 
de imprensa no Brasil e no mundo, a maior ameaça a caracterizar censura era proveniente do poder executivo, eventualmente do poder legislativo. Contudo, com o fenômeno da judicialização da política, o judiciário à luz dessa decisão poderia estar despontando, no contexto democrático pós-1988, como a principal e controversa fonte de medidas restritivas à liberdade de imprensa. Alguns segmentos da sociedade - remanescentes decadentes de oligarquias ressignificadas - teriam identificado o discurso técnico-jurídico como forma de preservar seus interesses agindo no direcionamento de decisões judiciais, ao envoltório de um suposto judicialismo político. Estaria se desenhando no horizonte político brasileiro uma nova forma de censura, a censura judiciária, a sinalizar ameaça de retrocesso político, à luz do que pondera Anastaplo (2002).

Como ficou demonstrado no julgamento da MCRecl. $n^{\circ}$ 9.428, cujo conteúdo envolve possível censura prévia ao jornal $O$ Estado de São Paulo em razão de publicação de matérias jornalísticas tocantes ao empresário Fernando Sarney, filho do Presidente do Senado José Sarney, denotando a participação do primeiro em supostas condutas criminosas (matérias elaboradas com informações baseadas pelos elementos indiciários e probatórios colhidos na Operação Boi Barrica da Polícia Federal, portanto informações obtidas de forma lícita), aquele veículo de mídia foi objeto de ação inibitória à divulgação dos fatos, tendo sido a cautelar concedida por desembargador membro do Tribunal de Justiça do Distrito Federal, politicamente indicado pelo senador.

É de se questionar se uma liberdade fundamental - como a liberdade de imprensa - que tem a pretensão de ser universal, pode ficar à mercê da boa vontade e discricionariedade de um julgador ou colegiado de magistrados, por carecer-lhes legitimidade democrática, uma vez que ingressos na carreira da magistratura por concurso de 
provas e títulos, e não por eleição. A experiência histórica de alguns países nos leva mesmo a refletir se uma corte constitucional teria condições de resistir aos apelos, influências, seduções ou mesmo ameaças de regimes com vocações autoritárias. Note-se que "há juízes em Berlim", mas mesmo esses sucumbiram ao nazismo. Sabe-se que a mais alta corte da nação compõe-se de julgadores escolhidos sob indicação política para atuarem como defensores da Constituição, quando a história brasileira - e até mesmo a universal - já demonstrou em vários momentos a condescendência, até mesmo a convivência e tolerância com regimes autoritários e ditatoriais.

Acreditava-se que a resposta do jornal Estado de São Paulo à censura que lhe fora estabelecida seria resolvida processualmente com a reclamação acima indicada. Contudo, a sucessão de eventos ao longo de meses evidenciou de forma clara como a democracia e a tutela dos direitos fundamentais estariam fragilizados materialmente em nosso cotidiano. Como nota Bucci (2009), em face da ação clara de setores oligárquicos e retrógrados da sociedade brasileira, percebemse ainda resistências contundentes em aceitar o Estado democrático e social de direito, persistindo a afronta aos direitos fundamentais. Tais setores estariam, assim, retardando a implantação do projeto republicano e a difusão de sua cultura no Brasil.

O que se identifica claramente no caso seria o emprego da tutela inibitória como instrumento processual de proteção de direitos da personalidade, ressignificada como mecanismo de censura a burlar a vedação constitucional que se lhe imprime pela constituição de 1988. A vontade da nação manifestada em seu poder constituinte originário veda a censura de todas as formas. Teríamos assim a utilização política do poder judiciário, que, sob o manto de defensor das virtudes democráticas, agora faria as vezes de censor, emprestando sua competência constitucional como administrador da 
jurisdição e solucionador de conflitos ao ato antidemocrático. A tutela judiciária, então, agiria como uma limitação ao direito fundamental da liberdade de imprensa, a revelar uma nova forma de censura.

$\mathrm{O}$ pano de fundo do caso concreto traz à baila considerações sobre o judicialismo político e seu papel no processo de modernização da sociedade brasileira. A má compreensão do judicialismo político já havia sido percebida por Werneck Viana (2008), cujo alerta apontava para os efeitos negativos que poderiam atingir o projeto democrático brasileiro. É de indagar-se se esse processo não está se tornando realidade. $\mathrm{O}$ caso concreto revelaria situação que superaria em muito qualquer possível equívoco. No caso em tela, perceber-se-ia a apropriação do discurso judicialista por setores oligárquicos aos olhos da nação, sem que resistências políticas bem articuladas provenientes da sociedade ou mesmo os recursos jurídico-constitucionais resultassem bem-sucedidos na reversão do fato. Ao contrário, levado o caso ao pretório excelso, a censura em via transversa resultou mantida. Teria se manifestado, destarte, uma versão degenerada de judicialismo político, desta feita antidemocrático e anticonstitucional. Neste sentido, revela-se a tensão dialética entre o discurso da dogmática constitucional e o conteúdo das duas decisões que terminaram por supostamente impor a censura prévia à luz do judicialismo político, agora conspurcado. O entendimento dominante na doutrina, capitaneada por Afonso da Silva (1998), é de que os direitos fundamentais são dispositivos dotados de eficácia plena e aplicação imediata. Assim, a liberdade de expressão - liberdade de imprensa -, por estar ínsita no rol do artigo $5^{\circ}$ da Constituição de 1988, tem eficácia plena, não podendo ser restringida ou limitada. Acrescente-se aí o $\S 2^{\circ}$ do artigo $220^{2}$, também da constituição, que

2 Artigo 220 - A manifestação do pensamento, a criação, a expressão e a informação, sob qualquer forma, processo ou veículo não sofrerão qualquer restrição, observado o disposto nesta Constituição.

http://www.ucp.br/html/joomlaBR/lexhumana/lexhumana.htm 
veda toda e qualquer forma de censura.

Evidente resta o impacto provocado pela decisão do Supremo Tribunal Federal no exercício da liberdade de imprensa no mundo jurídico. Devemos ponderar de que modo se deveria, doravante, compreender o conteúdo da liberdade de expressão e a sua extensão, nos moldes da reflexão que nos é trazida por Fiss (2009), quando analisa o impacto da decisão da U.S. Supreme Court no Pentagon Papers case de 1971. Para este fim, caberia precisar inicialmente o conceito de censura, suas formas de manifestação bem como a eventual censura resultante da ação orgânica do poder judiciário.

Censura, de uma forma apriorística, pode ser compreendida como qualquer juízo prévio de valor que é feito por terceiro a respeito do conteúdo de uma informação, determinando a sua reformulação ou supressão parcial ou total. Tal censura fere a liberdade de imprensa. O melhor julgador do conteúdo da mídia são os leitores e os que acompanham o debate público. Ela se caracteriza de modo expresso pela presença de censores nas redações dos jornais ou sutilmente como em alguns países, onde se denomina eufemisticamente de "adequação de conteúdo" à "verdade" oficial então temporariamente dominante. Em tais redutos de "ridículos tiranos" que insistem em povoar a "América católica", como alertava Caetano Veloso, a liberdade de expressão e de imprensa é plena, desde que consista em se expressar e publicar apenas a favor do governo.

Igualmente, cabe apontar e trazer à luz do debate acadêmico se o poder judiciário de forma proativa por meio do judicialismo político poderia, no exercício de sua competência orgânica, impor restrições a meios de comunicação, sem implicar censura ou violação da constituição, como entendeu a maioria dos ministros do pretório

$\S 2^{\circ}-$ É vedada toda e qualquer censura de natureza política, ideológica e artística. 
excelso. Entendemos que não. E, a partir dos casos concretos assinalados, ainda determinar o quadro constitucional em que isso poderia ter ocorrido no Brasil, analisando, criticando e apontando diretrizes para aperfeiçoar a atuação judiciária na tutela dos direitos fundamentais.

Do mesmo modo, como no caso em tela pode ter-se configurado a censura judiciária contornando a vedação constitucional existente, como entendemos, nos alinhando à corrente minoritária do pretório excelso, o discurso utilizado para proteger o direito à intimidade na ação inibitória pode reincidir novamente sobre a liberdade de imprensa ou, quiçá, atingindo outro direito fundamental. Se restar comprovada a hipótese, ter-se-ia demonstrado o poder judiciário como censor anticonstitucional, verdadeira aberração em um contexto de estado democrático de direito. A reflexão versa, portanto, a proteção e a guarda da constituição e dos valores cristalizados no artigo $5^{\circ}$, como pressuposto para a consolidação da democracia e construção da cidadania no Brasil.

Segundo Liern (2002), a liberdade de imprensa reflete o próprio Estado democrático de direito, pois é pela pluralidade de órgãos de imprensa de tendências variadas que o cidadão pode formar a sua cosmovisão e participar do debate público da sociedade. A fim de realizar tal objetivo, é de excluir-se toda possibilidade de ingerência externa ao exercício dessa liberdade, bem como de qualquer modalidade de censura prévia, sem embargo do dever de ética no jornalismo, do cometimento com a verdade e do compromisso democrático. Eventuais excessos e abusos no exercício da liberdade de imprensa devem ser punidos à luz da responsabilidade civil e, eventualmente, criminal.

Na dogmática constitucional, com base na doutrina de Sarlet (2009) e Gomes Canotilho (1993), temos que o debate contemporâneo 
em torno dos direitos fundamentais volta-se de modo contundente para a sua efetivação. $O$ processo de formalização constitucional e mesmo a expansão do núcleo de direitos fundamentais cederia destaque hodiernamente às resistências de ordem política e orçamentária à sua materialização - reserva do possível. Mesmo no que se refere aos direitos fundamentais que independem de prestações positivas pelo Estado, em termos materiais ou financeiros, como é o caso da liberdade de imprensa, poderíamos identificar uma tendência ao emprego da técnica jurídica e do poder judiciário como instrumento de cerceamento dessa liberdade no estabelecimento de uma censura em via transversa.

Assim sendo, como pondera Morange (1985), seria possível afirmar que estamos testemunhando verdadeiro retrocesso no plano de alguns direitos fundamentais, pois travamos combates que já se supunham encerrados com o triunfo das revoluções liberais na Europa no século XIX, quando deveríamos estar avançando em outras demandas sociais mais condizentes com o tempo atual. A censura prévia é sintoma de regimes autoritários. Há que se questionar, portanto, o quão maduro e consolidado se encontra o Estado democrático de direito no caso brasileiro.

No Brasil, podemos identificar o debate acima pelo marco jurisprudencial no qual este trabalho se baseia, partindo-se dos julgados do STF, a ADPF 130-DF e a MCRecl. no 9.428, ambas julgadas em 2009. Neles percebemos a relevante controvérsia constitucional sobre a liberdade de imprensa e a censura prévia. É de se notar que a reclamação está em uma relação de pertinência temática direta com a ADPF 130, uma vez que a questão de fundo é a liberdade de imprensa. A reclamação buscou a tutela da liberdade de imprensa plena, tendo em vista o caráter transcendente das razões determinantes da ADPF. A liberdade de imprensa e a problemática envolvendo a censura prévia 
já havia sido objeto de análise por ocasião do julgamento pelo STF da ADPF 130-DF, quando o pretório excelso declarou inconstitucional a lei de imprensa, a Lei no 5.250/67. Relator para a ação, o Min. Ayres Brito assim ponderou:

O corpo normativo da constituição brasileira sinonimiza liberdade de informação jornalística e liberdade de imprensa, rechaçante de qualquer censura prévia a um direito que é signo e penhor da mais encarecida dignidade da pessoa humana, assim como do mais evoluído estado de civilização. [...]. Não há liberdade de imprensa pela metade ou sob as tenazes da censura prévia, inclusive a procedente do poder judiciário, pena de se resvalar para o espaço inconstitucional da prestidigitação jurídica. (Ementa da ADPF 130DF, p. 4 e 5)

\section{A censura revisitada}

O Exmo. Ministro do Supremo Tribunal Federal, Celso de Mello, quando do julgamento da medida cautelar na reclamação $\mathrm{n}^{\circ}$ 9.428, em 10 de dezembro de 2009, a par do Exmo. Ministro Ayres Brito, também construiu marcante defesa da liberdade de imprensa, que deve ser exercida sem peias de qualquer natureza, proveniente de qualquer das funções estatais.

Por ocasião do julgamento da ADPF 130-DF, o Min. Celso de Mello já havia recordado a Conferência Hemisférica sobre a liberdade de expressão, realizada no México, em 1994, que terminou com a Declaração de Chapultepec, indicando entre tantos princípios:

II - Toda pessoa tem o direito de buscar e receber informação, expressar opiniões e divulgá-las livremente. Ninguém pode restringir ou negar esses direitos.

V - A censura prévia, as restrições à circulação dos meios ou à

http://www.ucp.br/html/joomlaBR/lexhumana/lexhumana.htm 
divulgação de suas mensagens, a imposição arbitrária de informação, a criação de obstáculos ao livre fluxo informativo a as limitações ao livre exercício e movimentação dos jornalistas se opõem diretamente à liberdade de imprensa. (Grifo no original) (ADPF 130-DF, p. 146)

Na MCRecl. $\mathrm{n}^{\circ}$ 9.428, o Ministro Celso de Mello faz a seguinte assertiva:

Hoje, a censura, e eu assim a identifico, tem sido tão abusivo o comportamento de certos magistrados e tribunais em nosso país. Hoje, o poder geral de cautela é o novo nome da censura judicial em nosso país. E isso é muito grave, pois nos faz voltar ao passado colonial (sic).

Tal assertiva demonstra que, passados vinte e sete anos da redemocratização do País, e quase vinte e um anos da promulgação da Constituição de 1988, poderíamos identificar a fragilidade da nossa magna charta em assegurar as liberdades públicas, desta feita não tanto por ameaça originária do Poder Executivo, mas sim em razão de um judicialismo político distorcido e degenerado, hoje empregado politicamente em muitos casos como instrumento para suspensão das conquistas democráticas e dos direitos fundamentais.

\section{Conclusão}

Imperioso torna-se lembrar a mensagem sinalizada pelos inconfidentes mineiros do século XVIII: libertas quae sera tamen. Ou mesmo a primeira parte do moto da revolução francesa - liberdade, igualdade e fraternidade. Entre tantos outros que poderíamos lembrar. Quão tardia ainda será nossa liberdade? Quanto mais ainda temos que esperar pela liberdade na sociedade brasileira? Esperamos que ela não 
precise reviver a experiência de um regime de exceção, de qualquer tendência ideológica, para perceber a importância da liberdade e da imprensa como garantidor deste valor tão caro ao ser humano. Neste momento, devemos olhar para o constitucionalismo norteamericano e aprender com a sua experiência política, notadamente com a lendária primeira emenda constitucional à constituição de 17 de setembro de 1787, que até hoje assegura a liberdade na américa. Enfim, não podemos perdê-la novamente a fim de aprender o seu valor e significado.

\section{Referências Bibliográficas.}

AFONSO DA SILVA, José. Aplicabilidade das normas constitucionais. 3. ed. São Paulo: Malheiros, 1998.

ALEXY, Robert. Teoria dos direitos fundamentais. São Paulo: Malheiros, 2008.

ALLAND, Denis et RIALS, Stéphane. Dictionnaire de la culture juridique. Paris: Quadrige/Lamy-PUF, 2003.

ALVES MACIEL, Débora. Sentidos da judicialização da política: duas análises. Disponível em: www.scielo.br/pdf/m/n57/a06n57.pdf. Acesso em: 2 mar. 2010.

ANASTAPLO, George. Censorship. In: The new encyclopaedia britannica. 15. ed. Chicago: Encyclopaedia Britannica, 2002. Vol 15.

BARBOSA, Cláudia Maria. O processo de legitimação do poder judiciário 
brasileiro. Disponível em: www.conpedi.org/manaus/arquivos/ Anais/Claudia\%20Maria\%20Barbosa.pdf. Acesso em: jan. 2010.

BARROSO, Luís Roberto. Judicialização, ativismo judicial e legitimidade democrática. Disponível em: www.oab.org.br/oabeditora/users/ revista/1235066670174218181901.pdf. Acesso em: jan. 2010.

BRASIL. Supremo Tribunal Federal. Brasília. ADPF 130 - DF, de 30/04/2009. Disponível em: www.stf.jus.br/?id=605411\&tipo=AC\& descrição=inteiro \%20teor\%20ADPF\%20/\%20130. Acesso em: 11 mar. 2010.

BRASIL. Supremo Tribunal Federal. Brasília. MCRecl. 9428, de 10 de dezembro de 2009. Disponível em: /www.stf.jus.br/arquivo/cms/ noticiaNoticiaStfArquivo/anexo/Rc19428RelVoto.pdf. Acesso em: 11 mar. 2010.

BRASIL. Supremo Tribunal Federal. Brasília. Informativo n. 576, 22-26 fev. 2010. Disponível em: http://www.stf.jus.br//arquivo/ informativo/documento/informativo576.htm. Acesso em: 11 mar. 2010.

BUCCI, Eugenio. A imprensa e o dever de liberdade. São Paulo: Contexto, 2009.

CASTANHO DE CARVALHO, Luís Gustavo Grandinetti. Liberdade de informação e o direito difuso à informação verdadeira. 2. ed. Rio de Janeiro: Renovar, 2003.

CITTADINO, Gisele. Poder judiciário, ativismo judicial e democracia. In: SEMINÁRIO TEMÁTICO CONTROLES DEMOCRÁTICOS E 
RESPONSABILIDADE PÚBLICA, no XXV Encontro da Associação Nacional de Pós-graduação e Pesquisa em Ciências Socias (ANPOCS), Caxambu, Minas Gerais, 16-20 out. 2001.

DE SOUZA, Sérgio Ricardo. Controle judicial dos limites constitucionais à liberdade de imprensa. Rio de Janeiro: Lumen, 2008.

DE SOUZA SANTOS, Boaventura. A judicialização da política. Disponível em:www.ces.uc.pt/opinião/brs/078.php. Acesso em: 3 mar. 2010.

FISS, Owen M. Liberalism divided - Freedom of speech and the many uses of state powers. Boulder: Westview, 2009.

FISS, Owen M. The irony of free speech. London: Harvard University Press, 1996.

GOMES CANOTILHO, José Joaquim. Direito constitucional. Coimbra: Almedina, 1993.

LIERN, Göran Rollnert. La libertad ideológica em la jurisprudencia del Tribunal Constitucional (1980-2001). Madrid: Centro de Estudios Políticos y Constitucionales, 2002.

MILTON, John. Areopagítica - Discurso pela liberdade de imprensa ao parlamento da Inglaterra. Rio de Janeiro: Topbooks, 1999.

MOON, Richard. The constitutional protection of freedom of expression. Toronto: University of Toronto Press, 2000.

MORANGE, Jean. Droits de l'homme et libertés publiques. 5. ed. Paris: 
PUF, 1985.

RABAY GUERRA, Gustavo. A expansão do poder judicial no constitucionalismo democrático: distorção sistêmica ou necessidade contemporânea? Disponível em: www.buscalegis.ufsc.br/revistas/ files/journals/2/articles/32552/public/32552-39665-1-PB. Acesso em: 3 mar. 2010.

RIZZINI, Carlos. Liberdade de imprensa. São Paulo: Mantiqueira, 1998. RUFINO DO VALE, André. Eficácia dos direitos fundamentais nas relações privadas. Porto Alegre: Sérgio Fabris, 2004.

SARLET, Ingo Wolfgang. A eficácia dos direitos fundamentais. 10. ed. Porto Alegre: Livraria do advogado, 2009.

SIQUEIRA CASTRO, Carlos Roberto. A constituição aberta e os direitos fundamentais. Rio de Janeiro: Forense, 2003.

RIBAS VIEIRA, José; LACOMBE CAMARGO, Margarida Maria e GARRIDO DA SILVA, Alexandre. Brasil nas mãos dos tribunais. Revista VERSUS. Rio de Janeiro, ano I, n. 2, pp. 75-84, ago. 2009.

RIBAS VIEIRA, José (Coord.), SOARES BENTES, Hilda Helena (Coord.), LACOMBE CAMARGO, Margarida Maria (Coord.) e GOMES, Maria Paulina (Coord.). Direitos à intimidade e à vida privada. Curitiba: Juruá, 2008.

WERNECK VIANA, Luís. A judicialização da política e das relações sociais no Brasil. Rio de Janeiro: Revan, 1999.

WERNECK VIANA, Luís. Entre princípios e regras - cinco estudos 
de caso de ação civil pública. Caderno CEDES. Rio de Janeiro, ano I, n. 1, mar. 2005.

WERNECK VIANA, Luís. Dezessete anos de judicialização da politica. Disponível em: www.scielo.br/pdf/ts/v19n2/a02v19n2.pdf. Acesso em: 3 mar. 2010.

WERNECK VIANA, Luís. O ativismo judicial mal compreendido. Boletim CEDES [on-line]. Rio de Janeiro, jul./ago. 2008, pp. 03-05. Disponível em: http://www.cedes.iuperj.br. ISSN: 1982-1522. Acesso em: 24 fev. 2010. 